\title{
Intraempreendedorismo no setor público por meio de ações formativas e educativas das escolas de governo brasileiras ${ }^{1}$
}

\author{
Alcielis de Paula Neto, Magnus Luiz Emmendoerfer e Stela Cristina Hott Corrêa
}

\section{RESUMO}

Melhorias interorganizacionais das instituições públicas passam pela ressignificação do seu capital humano, inclusive no que tange às competências empreendedoras. Nesta perspectiva, as Escolas de Governo (EGs) podem contribuir com a formação e capacitação de funcionários públicos. Assim, o objetivo aqui proposto é compreender as evidências de diretrizes educativas e formativas em prol do intraempreendedorismo no setor público por intermédio das EGs. Para tanto, foi realizado um estudo de casos múltiplos com três Escolas de Governo brasileiras dos três níveis federativos (federal, estadual e municipal). As entrevistas em profundidade foram submetidas à análise de conteúdo apoiadas no software IRAMUTEQ. Os resultados apontam a projeção da inovação como um pseudoempreendedorismo e a insinuação de diretrizes para um possível processo de educação para o empreendedorismo de servidores públicos, o que os tornaria potenciais intraempreendedores. Dentre essas diretrizes, destacam-se a análise do contexto, o perfil do aluno, os métodos de ensino e aprendizagem, aspectos jurídicos-legais, a adequação da infraestrutura e o papel dos facilitadores (mentores). Conclui-se que as EGs analisadas contribuem com a criação do valor público e valorização da imagem das organizações públicas por meio da ação intraempreendedora de seus servidores.

Palavras-Chave: escolas de governo; formação e qualificação; servidores públicos; educação para o empreendedorismo; IRAMUTEQ.

\section{Intrapreneurship in the Public Sector through Formative and Educational Actions of Brazilian Schools of Government}

\section{ABSTRACT}

Interorganizational improvements in public institutions include the resignification of their human capital, in addition to entrepreneurial skills. In this perspective, Schools of Government (SG) can contribute to the training and qualification of public officials. Thus, the objective proposed here is to understand the evidence of educational and training guidelines in favor of intrapreneurship in the public sector through SG. To this end, a multiple case study was carried out with three Brazilian Schools of Government at the three federal levels (federal, state and municipal). Indepth interviews were submitted to content analysis supported by the IRAMUTEQ software. The results point to the projection of innovation as a stepping stone of entrepreneurship and the hint of guidelines for a possible education process for the entrepreneurship of public servants, which would make them potential intrapreneurs. Among these guidelines, we highlight the analysis of the context, the student's profile, the teaching and learning methods, legal aspects, the adequacy of the infrastructure and the role of the facilitators (mentors). It is concluded that the analyzed SG's contribute to the creation of public value and enhancement of the image of public organizations through the intra-entrepreneurial action of their employees.

Keywords: schools of government; training and qualification; public servants; entrepreneurship education; IRAMUTEQ.

1 Agradecimentos ao Conselho Nacional de Desenvolvimento Científico e Tecnológico - Brasil (CNPq-Processos 408437 / 2016-2; 309363 / 2019-5), à Fundação de Pesquisa de Minas Gerais (FAPEMIG - Processo PPM00049-18). Agradecemos também as sugestões e recomendações dos avaliadores anônimos, reiterando a efetiva contribuição para o desenvolvimento das ideias e refinamento científico deste trabalho.
Recebido em: 26/05/2020 Revisado em: 08/02/2021 Aprovado em: 30/04/2021

Check for updates

Alcielis de Paula Neto (iD, Universidade Federal de Juiz de Fora, Brasil

Doutor

alcielisneto@gmail.com

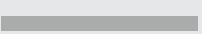

Magnus Luiz

Emmendoerfer (iD),

Universidade Federal de Viçosa, Brasil Doutor

magnus@ufv.br

Stela Cristina Hott Corrêa (D),

Universidade Federal de Juiz de Fora, Brasil Doutora

stelachc@gmail.com 


\section{Introdução}

Melhorar o desempenho intraorganizacional das instituições públicas é prioridade para muitos estudiosos da Administração Pública contemporânea (Najmaei \& Sadeghinejad, 2016; Shand \& Hyde, 2016). Os desafios, neste sentido, incluem orçamentos rígidos, escrutínio político, demandas sociais acentuadas (Arnold, 2019), além do recorrente e dispendioso problema das descontinuidades de projetos e programas em função das transições governamentais. Existem estereótipos e preconceitos ligados à morosidade no trabalho, burocracias inibidoras e contenções da criatividade e das soluções ágeis (Strategic Direction, 2020). Há ainda o agravante das privatizações (Warner, Aldag, \& Kim, 2020), terceirizações junto ao mercado (Cabral \& Ménard, 2019; Pugalis, Davidson, McLeay, \& Round, 2016), e transferência de funções ao terceiro setor (Lubienski \& Perry, 2019), além dos impasses das parcerias público-privadas (Nayak, 2019).

Uma alternativa para se mitigar problemas internos nos órgãos públicos seria reconhecer e estimular o Empreendedorismo no Setor Público - ESP (Emmendoerfer, 2019), inclusive dotando agentes que atuam dentro dessas organizações de expertise empreendedora. Ou seja, habilitar o funcionário público no empreendedorismo para lidar com novos e diferentes paradigmas (Edoho, 2016; Shand \& Hyde, 2016). Com isso, o servidor teria a oportunidade de se transformar num agente de mudanças (Fuller \& DelliSanti, 2017), num intraempreendedor (Prieto, Phipps, \& Kungu, 2020) capaz de aprimorar os serviços nas organizações onde já atua (Arnold, 2019). Principalmente, criar valor público, melhorar a estrutura de governança e favorecer a coprodução nestas entidades (Liddle, 2016). Seria um "sopro de vida necessário para regenerar o ambiente" (Quinn \& Courtney, 2016, p. 130).

A promoção do engajamento do servidor público no empreendedorismo perpassa por maneiras inovadoras de se trabalhar, pelo estímulo de novas aprendizagens e trocas de conhecimentos (Liddle \& McElwee, 2019). Trata-se de fortalecer e não deixar arrefecer as suas habilidades técnicas, normalmente atestadas nos concursos, além de incorporar novas habilidades em função de um processo de educação para o empreendedorismo (Rocha, 2012) no ensejo de novas competências (Shand \& Hyde, 2016; OCDE, 2017)

Neste contexto, as Escolas de Governo (EG) brasileiras têm um papel preponderante. Sua missão é revigorar as capacidades laborais dos funcionários públicos e atualizá-los no desenvolvimento de novas habilidades e competências por meio de ações formativas e educativas. Resta saber até que ponto estas instituições do staff governamental, nas diferentes esferas e poderes, estão atentas à aderência do empreendedorismo no setor público, estimulando, assim, o intraempreendedorismo nos servidores que atuam nas repartições. Daí, questiona-se, em que medida as Escolas de Governo evidenciam diretrizes educativas e formativas para o intraempreendedorismo no setor público?

Buscando resposta para essa questão, três Escolas de Governo no âmbito do executivo nacional, estadual e municipal no Brasil, respectivamente, a ENAP de Brasília-DF, a Fundação João Pinheiro de Minas Gerais e o IMAP de Curitiba-PR são o lócus deste estudo, caracterizando-o 
como uma análise multicasos. Neste sentido, o objetivo deste trabalho é compreender as evidências de diretrizes educativas e formativas em prol do intraempreendedorismo no setor público por intermédio das EG. Os resultados do trabalho lançam uma lente sobre o modus operandi destas instituições e ajudam a compreender suas ações estratégicas de capacitação de servidores na trilha do empreendedorismo e o que pode ser derivado desse processo.

Portanto, ao evidenciar a relação entre a Escola de Governo e a educação para o empreendedorismo no setor público, a pesquisa apresenta como contribuições gerenciais a indicação de práticas favorecedoras do desenvolvimento do intraempreendedorismo no servidor público a saber: (1) a seleção de candidatos efetivamente vocacionados para a ação empreendedora e empáticos à geração do valor público; (2) o uso de metodologias ativas; (3) a vivência de experiências em laboratórios de inovação; (4) o apoio de mentorias. Outra contribuição da pesquisa é mostrar como 0 intraempreendedorismo nas organizações públicas valorizam sua imagem organizacional pela presença de funcionários polivalentes e autorrealizados capazes de contribuir com as demandas sociais por meio da geração de valor público. Como contribuição acadêmica são apontadas sugestões para uma pesquisa qualitativa e uma pesquisa quantitativa com indicação das hipóteses a serem testadas. O incremento teórico se evidencia pela busca da sintonização da autoeficácia de Bandura (1997), com a consolidação da noção de intraempreendedorismo no setor público como estratégia de fortalecimento da moral do servidor que poderá acreditar mais no seu próprio potencial de trabalho e na sua capacidade para realizações de atividades inovadoras.

Além desta problematização introdutória, segue o subsídio de uma revisão de literatura e dos esclarecimentos quanto à metodologia empregada. Subsequente, tem-se a apresentação dos resultados que vai desencadear para o debate e as análises sobre possíveis diretrizes para o intraempreendedorismo no setor público, antes de se concluir as reflexões do presente estudo. Sugestões para pesquisas qualitativa e quantitativa são apresentadas ao final.

\section{Referencial teórico}

\section{Empreendedorismo no Setor Público (ESP)}

O empreendedorismo, entendido como a capacidade individual de identificar problemas e oportunidades para o investimento de recursos em soluções socialmente positivas, é passível de ocorrer em qualquer circunstância ou contexto, seja ele no público ou no privado (Najmaei \& Sadeghinejad, 2016). No setor público, o exercício empreendedor se manifesta de diferentes formas (Emmendoerfer, 2019), promovendo diferentes resultados, inclusive inovadores, gerando ganhos de efetividade (Gomes, 2017), além de melhorias de desempenho organizacional, detecção de 
oportunidades e empowerment gerencial (Arnold, 2019) configurados para o interesse público com benefícios socioeconômicos (Liddle \& McElwee, 2019). Neste sentido, o papel do servidor público torna-se preponderante, pois seu comportamento empreendedor se converte no intraempreendedorismo, por atuar em organizações já constituídas, nas quais ele não é o proprietário e sim funcionário (Liddle, 2016).

O intraempreendedorismo favorece a organização na renovação estratégica, no desenvolvimento de novos projetos (serviços e produtos) e na adequação da gestão de mudanças. Em contrapartida, os funcionários ampliam seus recursos pessoais num contexto de motivação e aprendizagem organizacional (Braunerhjelm, Ding, \& Thulin, 2018). No setor público, as práticas intraempreendedoras têm se revelado uma força motriz para as organizações públicas (Gomes, 2017) que se consolida no encontro de profissionais com aptidão para o comportamento intraempreendedor.

Trata-se do desenvolvimento de habilidades e competências para os empregados que devem atuar na ação (intra)empreendedora, na qual o exercício da criatividade, a desenvoltura de habilidades interpessoais, holísticas e conceituais devem ser observadas a favor da criação de valor público (Prieto et al., 2020). Essa discussão traz à tona o conceito de autoeficácia empreendedora derivado de Bandura (1987). Esse conceito faz referência ao julgamento das capacidades pessoais e habilidades dos indivíduos, considerando a autoavaliação do próprio esforço, perseverança e persistência diante da incerteza, coragem frente às ameaças, determinação de objetivos ambiciosos e busca da aprendizagem contínua. "A autoeficácia está relacionada conceitualmente e empiricamente com fenômenos ligados ao comportamento e à cognição de gestão" (Mendes, 2011, p. 32). Ou seja, a autoeficácia empreendedora pode ser potencializada individualmente por meio de treino, da capacitação e da educação, recrudescendo desta forma os níveis de atividades empreendedoras nas pessoas (Mendes, 2011).

Assumir riscos, mostrar iniciativa, ou seja, agir proativamente, apresentar novas ideias e pleitear a inovação não é uma prerrogativa só de executivos de alto escalão e proprietários de organizações, pois também dizem respeito aos colaboradores internos (Mustafa, Gavin, \& Hughes, 2018). Na ação intraempreendedora, o servidor público estará à frente do vislumbre de oportunidades (Arnold, 2019), reversão de ameaças enquanto considera os riscos inerentes às soluções (Quin \& Courtney, 2016), incertezas do contexto (Mustafa et al., 2018), ações pragmáticas (Leyden \& Link, 2015) e inovação disruptiva entendida na lógica schumpeteriana das invenções e oportunidades inexploradas (Braunerhjelm et al., 2018).

\section{Educação para o Empreendedorismo (EpE)}

Fayolle (2000) infere sobre as possibilidades do desenvolvimento de competências empreendedoras por meio de programas apropriados, fazendo, assim, uma alusão às ações educativas em empreendedorismo. Esse é um "processo dinâmico e social onde indivíduos identificam oportunidades para inovar e transformar suas ideias em práticas num dado contexto social, cultural ou econômico" (CE, 2006, p. 8). Na educação para o empreendedorismo 
dois elementos são essenciais, a saber: o desenvolvimento das qualidades, atitudes e habilidades pessoais e o treinamento específico, ou seja, a vivência da prática empreendedora no dia a dia organizacional (Fellnhofer, 2019; Puni, Anlesinya, \& Korsorku, 2018), de forma a apontar seus fatores e desdobramentos como potenciais benefícios (Quadro 1):

Quadro 1 - Benefícios da Educação para o Empreendedorismo

\begin{tabular}{|c|c|}
\hline Fatores & Desdobramentos \\
\hline \multirow{6}{*}{ Fortalece a cultura empreendedora } & - Multiplica os empreendedores e empresários \\
\hline & - Mitiga o desemprego; \\
\hline & - Cria mais empregos, \\
\hline & - Reduz a pobreza \\
\hline & - Impulsiona o desenvolvimento econômico \\
\hline & $\begin{array}{l}\text { - Reduz o impacto emocional (desespero e angústia) no caso de demissões e/ou quebras de } \\
\text { contrato de trabalho }\end{array}$ \\
\hline \multirow{3}{*}{ Aumenta a intenção empreendedora } & - Desperta do desejo de empreender \\
\hline & - Vislumbre de outras fontes de renda, além de um salário proveniente de uma empresa formal. \\
\hline & - Gera maior garantia de que os projetos sairão do papel e serão implementados de fato \\
\hline \multirow{4}{*}{$\begin{array}{l}\text { Ajuda a nutrir habilidades críticas } \\
\text { e atitudes positivas em relação ao } \\
\text { trabalho }\end{array}$} & - Disposição e motivação para o trabalho \\
\hline & - Descolamento da zona de conforto \\
\hline & - Inconformismo com a manutenção do status quo \\
\hline & - Inquietação para resolução de problemas e desafios \\
\hline \multirow{2}{*}{$\begin{array}{l}\text { Contagia a autoeficácia } \\
\text { empreendedora }\end{array}$} & - Maior probabilidade de tradução das intenções em ações \\
\hline & - Energização e positivação de fatores psicológicos \\
\hline \multirow{3}{*}{$\begin{array}{l}\text { Fortalece o nível e o conteúdo das } \\
\text { aspirações pessoais }\end{array}$} & - Coragem para a tomada de decisões \\
\hline & • Ambição na realização de projetos \\
\hline & - Possibilidades de outras contribuições sociais à comunidade \\
\hline \multirow{2}{*}{$\begin{array}{l}\text { Ensina aos alunos os traços } \\
\text { comportamentais }\end{array}$} & - Melhora do relacionamento interpessoal \\
\hline & - Amplia os horizontes de poder e influência social \\
\hline
\end{tabular}

Fonte: Elaborado pelos autores a partir de Puni, Anlesinya e Korsorku (2018)

Hägg e Schölin (2018), comungando do primeiro quadrante do Quadro 1 anterior apelidam a EpE de "cavaleiro branco" para o enfrentamento de crises econômicas nas ações governamentais e destacam alguns detalhes em relação à mesma: a) pode-se criar cursos e programas que visam gerar aprendizado sobre empreendedorismo; b) pode-se focar em aprender para ou no empreendedorismo; c) pode-se criar aprendizado por meio do empreendedorismo.

Com foco nessa perspectiva Paula, Emmendoerfer e Azevedo (2018), discorrem então sobre a educação para o empreendedorismo diferenciando-a da educação empreendedora. A segunda está contida na primeira, sendo que esta última "centra-se na atividade meio, buscando revolucionar ou transformar os métodos, técnicas, ferramentas e modelos 
de ensino e aprendizagem tradicionais aplicáveis em quaisquer áreas do conhecimento" (Paula, Emmendoerfer, \& Azevedo, 2018, p. 84). Os autores empreendem um meta-estudo para delimitar os principais determinantes da EpE, quais sejam cursos e programas, infraestrutura, publicações, conjuntura econômica, professores, alunos, governos, instituições de ensino, aspectos socioculturais, ambiente de negócios, parcerias e métodos de ensino (sejam os tradicionais ou os experienciais).

Neste ensejo, Wraae e Walmsley (2020), entendem que a mentalidade e a capacidade empreendedora podem ser desenvolvidas por intermédio da EpE, ampliando os horizontes do comportamento e da ação empreendedora. Essa conduta, voltada introspectivamente para as organizações públicas, vai de encontro ao fortalecimento do intraempreendedorismo e à capacidade de dotação do capital humano atuante de novas habilidades e competências. Normalmente, as instituições responsáveis pela profissionalização e educação continuada dos servidores são as Escolas de Governo.

\section{As Escolas de Governo (EG)}

A profissionalização do capital humano que atua nas esferas governamentais é um dos pontos relevantes no incremento da administração pública e das reformas administrativas desejadas para as melhorias na prestação de serviços satisfatórios (Fonseca, Camões, Cavalcanti, Lemos, \& Palotti, 2019). Há preocupações quanto à capacidade de atendimento às demandas sociais, eficiência, otimização de despesas e principalmente desempenho da força de trabalho nas organizações públicas (Hollanda, Cardoso, Fernandes, \& Rosa, 2019). Estes mesmos autores mencionam a importância de uma burocracia profissional (servidores públicos) como condição necessária para o aprimoramento da capacidade administrativa do Estado, que precisa ser ampliada por meio do treinamento do servidor. Também pelo investimento na formação de funcionários públicos.

Nesta perspectiva, emerge o papel e as funções das Escolas de Governo (EG) que têm, dentre outras atribuições, a prerrogativa maior de formar, capacitar, qualificar, treinar, aperfeiçoar e, sobretudo, profissionalizar o servidor público (Evaristo, Batista-dos-Santos, Aguiar, Souza \& Franco, 2019). Portanto, é imperativo destacar a missão central desempenhada por essas instituições que tendem a realizar atividades de aprendizado com base em uma perspectiva aplicada, em consonância com o contexto específico do serviço público (Hollanda et al., 2019). Isso contribuiria no auxílio aos governos do alcance dos seus objetivos por intermédio do uso de treinamento da sua força de trabalho como meio de aumentar a eficiência, a inovação e a sua capacidade administrativa e, consequentemente de Estado legitimado.

Neste contexto, Fonseca, Meneses, Souza e Hollanda (2019), analisam as mudanças paradigmáticas que afetam o setor público e a ocorrência de inovações nas funções da gestão de pessoas, tendo em vista a adequação dos colaboradores internos aos novos modelos organizacionais a serem adotados. Neste caso, nota-se o extrapolamento da finalidade das Escola de Governo, exaltando o seu caráter tecnopolítico, ou seja, sua habilidade de gerar pessoas capazes de raciocinar, combinando julgamentos técnico e político (Matus, 2007). Desta forma, os agentes públicos devem ampliar 
seus horizontes de formação técnica e alcançar habilidades mais holísticas e interpessoais, inclusive com a aproximação de temas críticos e de fronteira no entorno da administração pública, tal como empreendedorismo.

Com efeito, imprimir uma consciência mais visionária na formação do servidor se faz mister em função das novas realidades que impactam o setor público. Essa formação de quadros, "reciclagem" de funcionários ou ainda criação de fóruns de debate nas três esferas de governo, como infere Pacheco (2000), pode significar uma reconfiguração do perfil do servidor.

Assim, Abdolhosseinzadeh e Abdolhamid (2020), analisam que nas sociedades modernas, as EG são encarregadas de estudar as instituições de governo e de educar os futuros governantes gestores e formadores de políticas públicas para se alcançar o sucesso. A capitalização das capacidades e competências desses atores contribui na estrutura de governança e geram conhecimento aplicado para o Estado para se resolver problemas tangíveis e transforma atores da administração pública em empreendedores públicos. Daí a necessidade de se compreender melhor essa relação entre Escolas de Governo e a ressignificação do potencial de trabalho do servidor por meio da ação empreendedora. Lembrando que essa ação, sistematizada no interior de uma organização que já existe, como é o caso dos órgãos públicos, vai configurar o intraempreendedorismo.

\section{- Procedimentos metodológicos}

Em função da abordagem do problema proposto (relação Escolas de Governo versus variações aplicadas do empreendedorismo) o desenho de pesquisa adotado foi de natureza essencialmente qualitativa, cujo objetivo geral sugeriu um tipo de pesquisa exploratória (Moser \& Korstjens, 2018). Apesar de amplamente estudados, tanto a noção de empreendedorismo quanto de educação para o empreendedorismo (EpE) e mesmo o intraempreendedorismo, o viés desses fenômenos no setor público ainda são incógnitas (Lopes, \& Lima, 2019). Muito anonimato também cerceia as funções e o papel das Escolas de Governo. Desta forma, buscou-se aqui uma maior familiaridade e aproximação destes temas, que já há um grau de imprecisão acentuado, bem como um maior diálogo, por meio de entrevistas, com pessoas que possuem experiências práticas com o problema pesquisado. A análise de exemplos que estimulem a compreensão do fenômeno em exposição dá a tônica deste trabalho qualitativo-exploratório.

Portanto, este é um estudo empírico com o emprego do método de estudos de casos múltiplos (Yin, 2015). Para fundamentar a escolha das escolas a serem investigadas foi realizada previamente uma pesquisa de dados secundários que apontou um universo estimado de mais de 300 Escolas de Governo em todo o país nas diferentes esferas e poderes. As unidades de análise foram selecionadas por serem "casos extremos" (Moser \& Korstjens, 2018) nas esferas municipal, estadual e federal. As escolas foram visitadas in loco no período de julho a setembro de 2019. Elas são a ENAP de Brasília-DF (âmbito federal), a Fundação João Pinheiro de Minas Gerais (âmbito estadual) e o IMAP da cidade de Curitiba-PR (âmbito municipal). O Quadro 2 detalha algumas informações sobre essas organizações: 
Quadro 2 - Detalhes das Unidades de Análise estudadas

\begin{tabular}{|c|c|c|}
\hline Organização & $\begin{array}{l}\text { Tempo de } \\
\text { Operação }\end{array}$ & Função Governamental \\
\hline ENAP & $\begin{array}{l}\text { Na ativa desde } \\
1986 \text { (35 anos) }\end{array}$ & $\begin{array}{l}\text { Atuação no âmbito federal da União, vinculada ao Ministério da Economia, com a } \\
\text { incumbência do desenvolvimento de competências nos servidores públicos }\end{array}$ \\
\hline FJP & $\begin{array}{l}\text { Na ativa desde } \\
1969 \text { (52 anos) }\end{array}$ & $\begin{array}{l}\text { Atuação no âmbito estadual, vinculado à SEPLAG do Estado de Minas Gerais, com } \\
\text { objetivos de pesquisa e ensino, além da formação e capacitação de servidores públicos. }\end{array}$ \\
\hline IMAP & $\begin{array}{l}\text { Na ativa desde } \\
1963 \text { (58 anos) }\end{array}$ & $\begin{array}{l}\text { Atuação no âmbito municipal, sendo uma autarquia vinculada à Prefeitura de Curitiba- } \\
\text { PR, com intuito de desenvolver metodologias de aperfeiçoamento contínuo da } \\
\text { Administração Pública. }\end{array}$ \\
\hline
\end{tabular}

Fonte: Elaborados pelos autores a partir dos respectivos sites institucionais das EGs pesquisadas (https://enap.gov.br/pt/; http://novosite.fjp. mg.gov.br/a-fjp/. https://www.curitiba.pr.gov.br/.)

A busca de dados primários foi empreendida com a alta cúpula de representantes destas instituições e com os demais funcionários indicados por eles. Portanto, a amostragem foi intencional e em bola-deneve, resultando em 19 indivíduos submetidos a uma entrevista qualitativa (Godoi \& Mattos, 2010), com tempo médio de 45 minutos. Desta forma, os dados foram coletados por meio de entrevista em profundidade (Duarte, 2011), com o apoio de um roteiro de entrevista (Yin, 2015). Neste caso, as temáticas abordas na condução das entrevistas foram: 1) a caracterização do sujeito entrevistado; 2) a caracterização das organizações em foco a partir dos depoimentos dos entrevistados; 3) a detecção das possibilidades de prospecção do empreendedorismo no setor público; 4) a identificação de marcos históricos consoantes com os objetivos da pesquisa; 5) os fatores influenciadores da trajetória histórica das organizações em estudo, bem como suas competências organizacionais.

Com efeito, os dados foram gravados e transcritos (Franco, 2018) para uma devida análise de conteúdo inspirada em Bardin (2016), com categorias de análise definidas a priori (baseadas nos fins e nos meios) respaldas pela revisão bibliográfica adotada. A posteriori, a utilização do software IRAMUTEQ endossou essas categorias adotadas.

Assim, os dados qualitativos foram analisados no IRAMUTEQ, um aplicativo que faz uma interface com a linguagem de programação $R$ (Ratinaud \& Déjean, 2009). Ao todo, as respostas dessas 19 entrevistas compuseram um corpus de 120 páginas de relatos de um documento convencional para a análise textual. Um corpus é uma coletânea de textos com caraterísticas homogêneas em torno do objetivo de pesquisa formando um banco de dados qualitativo (Mazieri, 2016). As saídas provenientes do IRAMUTEQ que suportaram a análise de conteúdo efetuada neste estudo foram a AFC (Análise Fatorial por Correspondência), a AS (Análise de Similitude) e a NP (Nuvem de Palavras) amparadas em Brito (2019).

A partir da análise fatorial por correspondência foi possível realizar associação do texto entre as palavras, considerando a frequência de incidência de palavras e as classes, representando-as em um plano cartesiano. De modo complementar, a partir do depoimento dos entrevistados, realizou-se a análise de similitude, que trabalha em cima da Teoria dos Grafos, de modo a identificar as ocorrências entre as palavras e as suas conexidades. Sendo 
assim, a nuvem de palavras agrupou determinadas palavras e as organizou graficamente em função das suas frequências (Ramos, Feijão, \& Melo, 2019). Desta forma, foi oportunizado um mapeamento mental dos pareceres dos entrevistados, que na condição de representantes das suas respectivas Escolas de Governo, fez emergir uma série de insights estruturantes de uma proposta para a EpESP. Derivadas deste protocolo, surgiram recomendações estimulantes do intraempreendedorismo nas organizações públicas.

\section{Resultados}

O objetivo deste trabalho é compreender as evidências de possíveis diretrizes educativas e formativas em prol do intraempreendedorismo no setor público por intermédio das Escolas de Governo. O entendimento desse aspecto lança luz sobre a maneira como as organizações públicas fortalecem suas capacidades e recursos internos, sendo, portanto, fatores estratégicos capazes de ressignificar este setor com a criação de valor público satisfatório.

Para seguir dentro dessas duas perspectivas de análise, o banco de dados qualitativos (corpus) foi submetido a uma análise de conteúdo fundamentada em Bardin (2016) e Franco (2018). O software IRAMUTEQ foi utilizado segundo as recomendações de Brito (2019), Camargo e Justo (2013), e Souza, Wall, Thuler, Lowen, \& Peres (2018). As saídas do IRAMUTEQ analisadas neste estudo foram a análise fatorial de correspondência (AFC), a análise de similitude (AS) e a nuvem de palavras (NP). Elas são apresentadas a seguir.

\section{Análise Fatorial de Correspondência - AFC}

A análise fatorial de correspondência faculta a compreensão do texto envolvendo as palavras e a frequência de incidência delas distribuídas em classes (Brito, 2019). As saídas do IRAMUTEQ mostram essa referida associação num plano cartesiano que ajuda a visualizar a proximidade entre classes ou palavras (Figura 1). Trata-se de uma representação gráfica que mostra o posicionamento das classes de vocábulos no corpus textual, por meio da qual se pode avaliar quais classes se complementam e concentram o corpus e quais se distanciam do centro e mostram certa especificidade (Ramos et al., 2019). Quanto mais distantes os elementos (palavras ou classes) estão entre si, mais distintos eles são. Isso não significa uma oposição semântica entre esses agrupamentos, uma vez que eles podem ser também complementares (Nascimento \& Menandro 2006).

A AFC foi originária de um corpus de análise de 19 textos, que correspondem ao retorno de respostas dos 19 entrevistados, segregados em 305 segmentos de textos (ST). Destes ST, 271 segmentos foram considerados para análise com um aproveitamento significativo de $88,85 \%$, resultado este positivo uma vez que a recomendação técnica de aproveitamento deve superar os 70\% (Camargo, 2005). Também constam 10.613 ocorrências (palavras, formas ou vocábulos), sendo 2.011 palavras 
distintas e 1.188 que aparecem uma única vez (Hapax). Essas ocorrências foram agrupadas nas classes apresentadas na Figura 1. Com significativas concentradas em quadrantes distintos e mostrando certas especificidades, as classes 3 e 4 estão posicionadas à esquerda do fator zero do gráfico e distanciadas entre si, apesar de alguns elementos de transição em comum entre as classes.

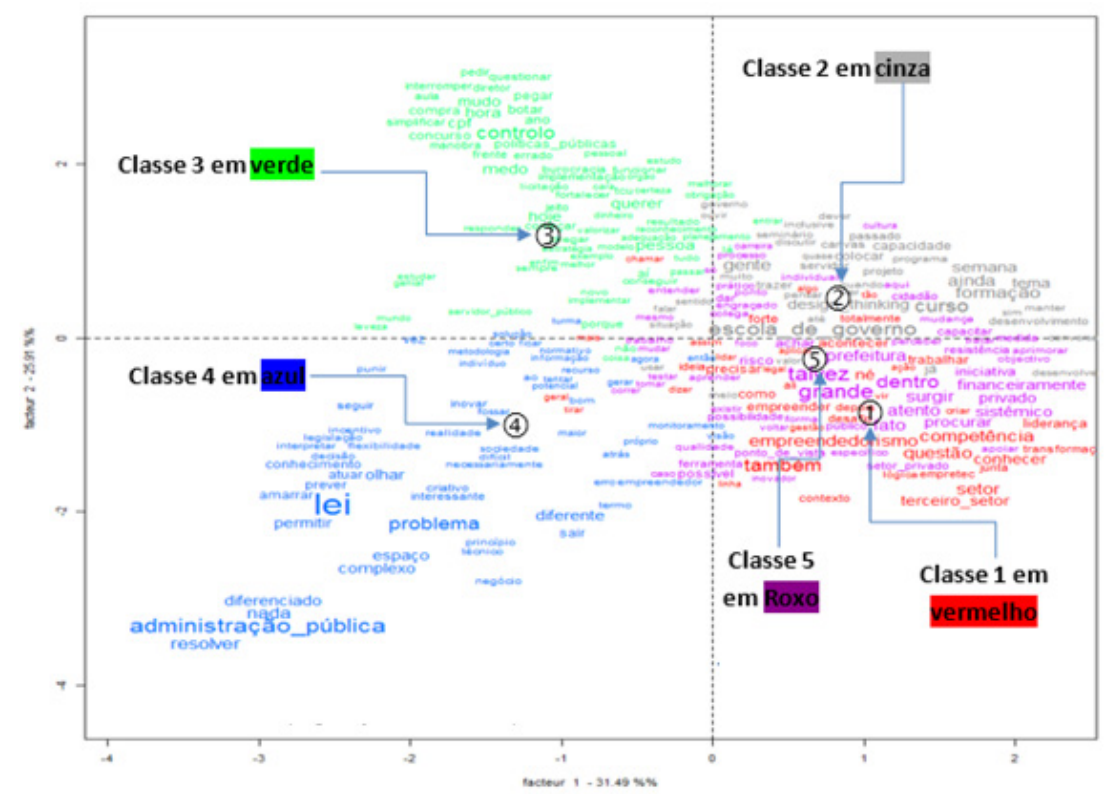

Figura 1. Análise Fatorial por Correspondência (AFC)

Fonte: Elaborado pelos autores a partir por meio do software IRAMUTEQ

O entrelaçamento entre as classes 1, 2 e 5 sugere uma provável complementariedade em torno de temas muito próximos, embora distintos. As classes 1 e 2 insinuam a presença do empreendedorismo como um conteúdo relevante das escolas de governo que aciona a competência do aluno para $\mathrm{o}$ ato de empreender, trabalhar, transformar e liderar. Termos como "empreender", "lógica empreendedora", "empreendedorismo", "ideia", "design thinking", "criar", "desafio", "liderança" e "transformação" sustentam essa inferência.

Observada isoladamente, a classe 2 sinaliza a presença das escolas de governo como instrumento de capacitação e formação do servidor. Nesta classe ressaltam palavras como "design thinking", "canvas", "curso", "seminário", "formação", "discutir" e "passado". Essas palavras colocam em evidência uma didática do passado em contraste com metodologias ativas que inserem o aprendiz no centro da construção do seu próprio conhecimento. Nessa mesma classe está em destaque o vocábulo "gente" indicando que a EpESP é acionada pelo esforço individual do aprendiz e pela iniciativa do professor-mentor que auxilia o aluno a enxergar suas competências e habilidades intraempreendedoras.

A classe 5 apresenta uma profusão de palavras com significado semântico diferentes, porém complementares, o que permite identificar uma certa associação entre elas. Essa classe aventa o potencial papel do estado na propulsão da capacitação para o empreendedorismo, mas coloca 
em evidência a ameaça e risco que a sua adoção possa representar aos interesses públicos, uma vez que está tradicionalmente associado aos valores da iniciativa privada. Com isso, as mudanças estão sujeitas à resistência, devendo ser processadas com atenção sem perder de vista o cidadão, beneficiário final do processo de capacitação. Além disto, as classes 1 e 5 apresentam uma superposição que coloca no mesmo espaço palavras como "privado", "lógica_empretec", "setor_privado", "terceiro_setor", "contexto", "ponto_de_vista" e "apoiar", que em conjunto evidenciam o contexto externo, notadamente o setor privado, como um ponto de referência ou benchmarking para o desenho de uma EpESP.

As classes 3 e 4, apesar de distantes e distintas em sua significação semântica, também apresentam complementariedade. Elas sinalizam o contexto externo das Escolas de Governo, o qual pode impactar negativamente ou positivamente a EpESP. "Políticas públicas", "leis", "burocracia", "administração pública", "espaço complexo", "sociedade", "flexibilidade", "interromper" sugerem que as ações das Escolas de Governo a favor da educação para o empreendedorismo sofrem os efeitos do ambiente externo, notadamente do ambiente governamental, representado pelas "políticas públicas" e "legislação", e do "ambiente social".

Isoladamente, a classe 3 também pode ser interpretada como a necessidade do controle da ação empreendedora do servidor por meio das políticas públicas. Esse controle pode estar associado ao medo ou receio do que possa dar errado se o "interesse pessoal" e o "dinheiro" forem os valores associados à implementação do empreendedorismo no setor público. Talvez por isso as palavras "burocracia" e "concurso" emergem com realce, sinalizando a necessidade de instrumentos tradicionais da gestão pública como mecanismo de "controle" da aplicação da atividade empreendedora.

Complementando a classe 3, a classe 4 realça a eventual presença da "legislação", representada também pela palavra "lei" como um instrumento diferenciado para "resolver" e "monitorar" os "problemas" nesse "espaço complexo" que é a "administração pública". Algumas palavras com menor incidência, que estão na direção do centro do gráfico, apontam que esse suporte jurídico-legal é provavelmente necessário para que o servidor possa atuar sem receios, bem como mostram que o amparo dos órgãos de controle são coisas um tanto quanto pensadas à parte, levando a crer que estes são dois eixos de trabalhos são favoráveis à EpESP e merecem atenção. Essas classes também apontam na direção do contexto externo das Escolas de Governo.

Desta forma, a AFC pode indicar que os entrevistados compreendem o papel das EG para a formação de competências empreendedoras dentro de uma proposta de EpESP, apesar dos percalços da operacionalização e da interface com mercado, gerando a necessidade de mecanismos de controle. Isto é uma evidência pela presença de palavras como "empreendedorismo", "inovação", "liderança", "iniciativa" e "competência", em paralelo às palavras "medo", "risco", "transformação", "individual”, "financeiramente”, "dinheiro", "controle" e "lei" (Swayne, Selznick, McCarthy, \& Fisher, 2019). Além disto, esta análise sinaliza a importância das metodologias ativas na formação para o intraempreendedorismo. 
Análise de Similitude - AS

A análise de similitude permite identificar as ocorrências simultâneas entre as palavras e suas conexidades (Brito, 2019, p. 46). Portanto, enquanto a análise fatorial de correspondência evidencia as palavras de acordo com sua incidência, sugerindo possíveis relações, a análise de similitude avança e apresenta as coocorrências entre as palavras, indicando com maior consistência a conexidade entre elas. Logo, ela auxilia a conhecer a estrutura do conteúdo de um corpus textual, possibilitando a sua visualização de outra forma. Ou seja, em relação às possibilidades de criação de um modelo de EpESP na perspectiva dos entrevistados a partir de vetores de análise que se sobressaíram nos depoimentos dos mesmos (ver Figura 2).

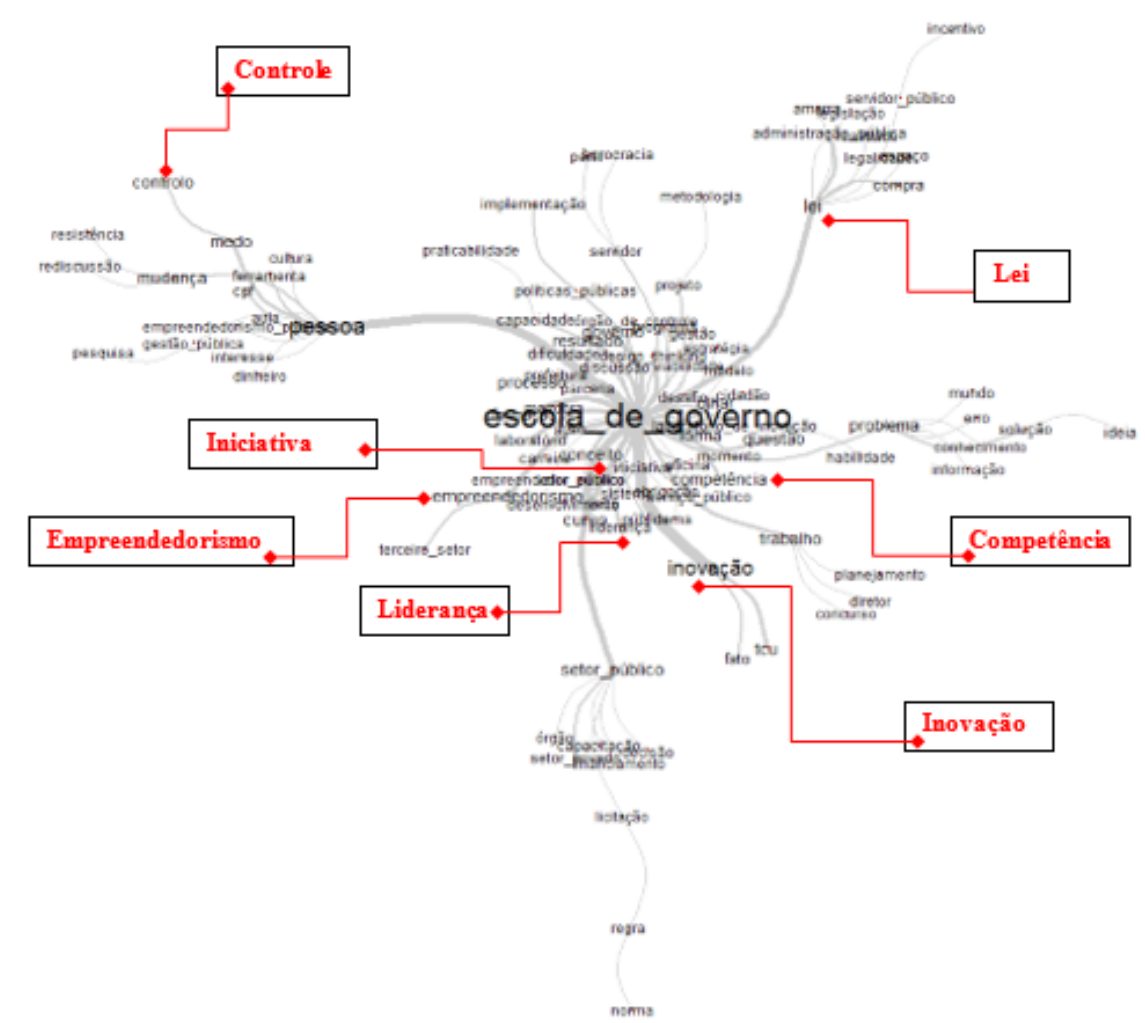

Figura 2 - Análise de Similitude (AS)

Fonte: Elaborado pelos autores a partir de um dos outcomes do IRAMUTEQ

$\mathrm{Na}$ árvore de coocorrência as palavras que se destacam nos discursos estão em evidência. A principal delas é a expressão conjugada "Escola de Governo", que se encontra no foco central e se aglutina em si com outras formas evocadas pelos entrevistados. A partir deste núcleo vem as principais ramificações com destaque para "inovação", "lei" e "pessoa". Aqui fica evidente as especificidades de "lei" e "pessoa" de um lado e a "inovação" de outro. No sentido da inovação estão as palavras associadas aos fundamentos da ação empreendedora, tais como "iniciativa", "competência", "habilidade", "liderança", "ideia", "informação", "conhecimento", "desenvolvimento", "problema" e "solução". A coocorrência dessas palavras insinua que o conhecimento e informação estão na base da inovação e que por meio 
da inovação se encontra a solução para os problemas. Usando uma lupa na "Escola de Governo" percebe-se que conectada a ela está o termo "laboratório_de_inovação". Essa conexão sugere a representatividade da EG como espaço embrionário para inovação no serviço público. Além disto, o "laboratório_de_inovação" também remete ao aspecto físico da infraestrutura das escolas de governo. Nota-se que na análise de similitude, a palavra "inovação" obteve maior destaque que o "empreendedorismo", muito embora ambas estejam associadas. Isso leva a crer que os entrevistados tomam a inovação a título de uma ação empreendedora, sinalizando que a EpESP está sendo feita de forma velada.

Em sentido oposto estão as palavras "lei" e "pessoa". Relacionadas à "lei" estão "servidor público", "compra" e "administração", o que sugere que as ações intraempreendedoras do servidor público devem estar sujeitas à legislação e que esse é um desafio para a EpESP. Associadas à "pessoa" estão os vocábulos "mudança", "medo", "cultura", "rediscussão" e "resistência". Essas palavras sinalizam que o aluno que pretende atuar no serviço público possa ter resistência à educação para o empreendedorismo, uma vez que há uma cultura aversa ao intraempreendedorismo no setor público, o qual é predominantemente associado ao setor privado. Relacionada à "pessoa" também se encontram os vocábulos "controle", "interesse" e "dinheiro". Neste ponto surgem três interpretações. A primeira subentende a pessoa como aquele controller responsável pelo monitoramento e fiscalização das ações do servidor. O segundo ponto de vista supõe que a "pessoa" (servidor) atua como o agente do empreendedorismo e da mudança. Mas, enquanto ser humano, a pessoa pode ser passível de agir segundo interesses pessoais (interesses) e monetários (dinheiro). Nesse caso, percebe-se uma possível conexão entre "lei" e "pessoa" dada pelo uso das ferramentas de controle por meio do aparato legal, como instrumento de salvaguarda do interesse coletivo. A terceira interpretação vê a "Lei" como uma força restritiva que precisa ser superada a favor do empreendedorismo no setor público, o que requer a reinterpretação do marco legal e/ou criação de regulamentos complementares.

Ao centro da "inovação", "pessoa" e "lei" estão as "escolas de governo" que na visão dos entrevistados têm a função de promover a inovação na função administrativa da máquina pública, sem deixar de evidenciar o papel da legislação para o controle dos interesses pessoais face os interesses públicos. Portanto, percebe-se nessa ilustração as interceptações e os entrelaçamentos entre os fundamentos do empreendedorismo e das funções das Escolas de Governo, insinuando pontos relevantes para a EpESP. Isso ajuda a entender melhor o tópico anterior da AFC e dialoga com Swayne, Selznick, McCarthy e Fisher (2019).

Na árvore de coocorrência as palavras que se destacam nos discursos estão em evidência (Brito, 2019, p. 47). A principal delas é a expressão conjugada "Escola de Governo" no foco central, que aglutina em si outras formas evocadas pelos entrevistados. A partir desse núcleo vêm as principais ramificações com destaque para "inovação", "lei" e "pessoa". Esta última, pela análise de conteúdo, fica subentendida como aquele "controller" responsável pelo monitoramento e fiscalização das ações do servidor. 
Importante notar nessa ilustração as interceptações e os entrelaçamentos entre os fundamentos do empreendedorismo e das funções das Escolas de Governo e as possíveis insinuações em prol da EpESP. Isso ajuda a entender melhor o tópico anterior da AFC e corrobora com Swayne et al. (2019).

\section{Nuvem de Palavras}

Uma das aplicabilidades do IRAMUTEQ é gerar a nuvem de palavras. Ela é uma análise do tipo lexical que ilustra a incidência de todas as palavras oriundas do corpus de entrevistas, permitindo agrupar e organizar as palavras de acordo com a sua frequência (Brito, 2019). Os vocábulos são reunidos numa figura onde a sua distribuição, localização, disposição gráfica e o tamanho da fonte são parâmetros que indicam a magnitude da sua frequência no corpus. A Figura 3 revela as principais palavras enumeradas no discurso dos entrevistados sobre a EpESP por ação das Escolas de Governo. As palavras maiores, colocadas no centro da figura, são aquelas com maior frequência no corpus, e as menores apresentam as menores frequências.

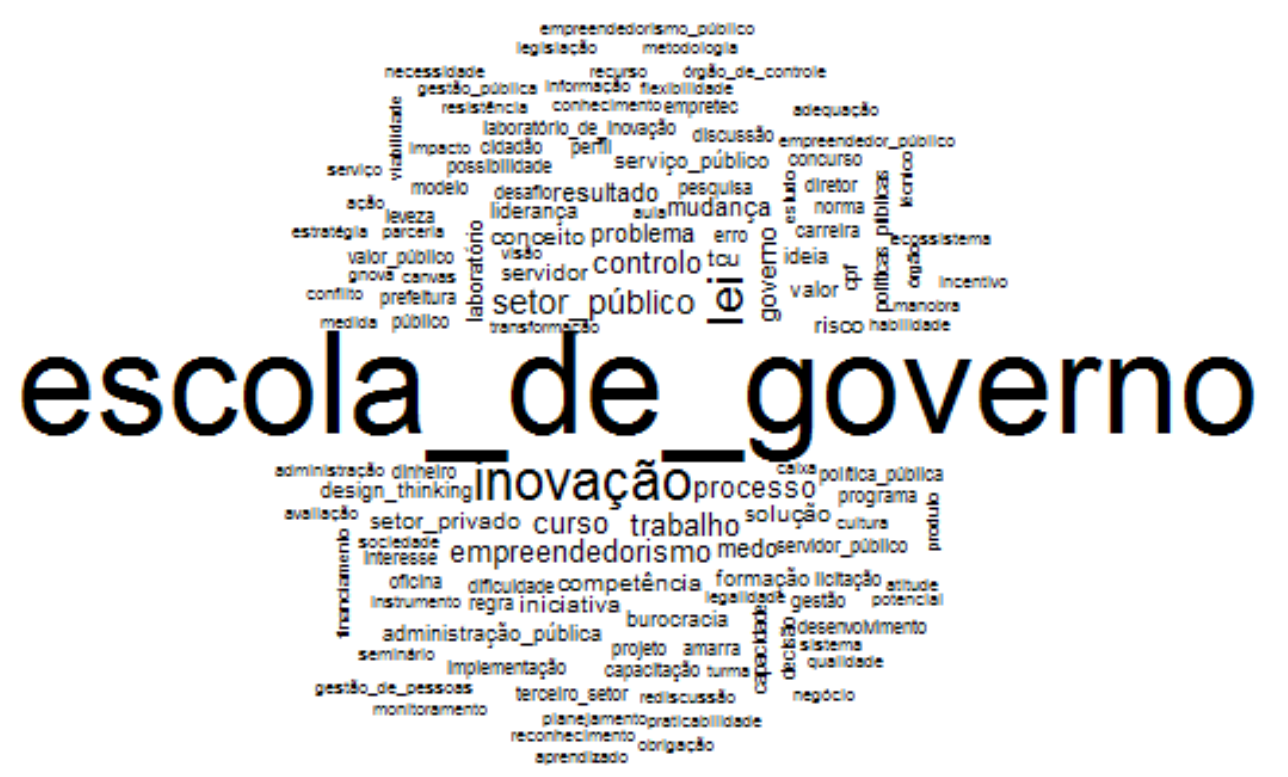

Figura 3 - Nuvem de Palavras (NP) da análise textual sobre a EpESP

Fonte: Elaborado pelos autores a partir de um dos outcomes do IRAMUTEQ

Observa-se, com o auxílio da análise de conteúdo efetuada a priori, que a centralidade e o exagero desproporcional da expressão "Escola de Governo" se devem ao fato dela traduzir o significado de outras cinco palavras (ENAP, FJP, IMAP, gente e escola de governo). A leitura flutuante (Bardin, 2016) permitiu uma maior familiaridade com o texto, bem como algumas impressões e orientações importantes. Uma delas é que a palavra "gente" foi empregada com múltiplos significados no discurso dos entrevistados, sendo ora como interjeição, ora como pessoa (cidadão), ora como dupla (sinônimo de "ambos"), ora como equipe, além de outros significados. Entretanto, na maioria dos casos, ela foi subentendida como Escola de Governo propriamente dita, afetando, assim, o impacto dessa expressão na nuvem de palavras. Desta forma, o corpus foi organizado de forma que quando "gente" 
tivesse o sentido de "Escola de Governo", ela fosse contada como "Escola de Governo". O mesmo se deu com ENAP, FJP e IMAP. As demais palavras de destaque endossam as análises anteriores do IRAMUTEQ.

\section{Discussão e implicações}

Os resultados trouxeram à tona os grupos de palavras e sua proximidade segundo a sua incidência (AFC), as correlações entre as palavras (análise de similitude) e a frequência das palavras por si só (nuvem de palavras). Agora, analisando detalhadamente esses resultados, é possível traçar as diretrizes educativas e formativas em prol do intraempreendedorismo no setor público por intermédio das Escolas de Governo. Esse esforço fez surgir preliminarmente as diretrizes de Educação em Empreendedorismo no Setor Público (Paula, Emmendoerfer \& Corrêa, 2020), as quais foram aperfeiçoadas e tratadas neste artigo como EpESP com os rumos orientadores de um processo para treinamento e capacitação do servidor a favor da ação empreendedora dentro da organização pública, enfatizando o intraempreendedor público. Ou seja, delinear parâmetros que possibilitem ao servidor se transformar em um agente de mudanças nas organizações públicas por meio do intraempreendedorismo com foco na criação de valor público. A Tabela 1 ilustra as diretrizes para a EpESP, as quais são explicadas a seguir.

Tabela 1 - Diretrizes para a Educação para Empreendedorismo no Setor Público

Educação para o Empreendedorismo no Setor Público (EpESP): Uma diretriz educativa para 0 intraempreendedorismo

\begin{tabular}{|c|c|c|c|}
\hline Diretrizes & Ações & Consequências & Depoimentos \\
\hline $\begin{array}{l}\text { Contexto em nível } \\
\text { macro, meso e } \\
\text { micro. }\end{array}$ & $\begin{array}{l}\text { Análise do macroambiente. } \\
\text { Análise de cenários. } \\
\text { Análise dos elementos } \\
\text { nacionais e internacionais. } \\
\text { Aspectos regionais, } \\
\text { institucionais e relacionados à } \\
\text { universidade. }\end{array}$ & $\begin{array}{l}\text { Identificação de } \\
\text { oportunidades para a } \\
\text { criação de valor público. } \\
\text { Manejo de incertezas. }\end{array}$ & $\begin{array}{c}\text { “...eu acho que sim, a chancela de um determinado } \\
\text { partido político impacta a escola. Eu acho } \\
\text { que tem sim determinados contextos em que } \\
\text { a importância da escola ela é reforçada a } \\
\text { depender da orientação política estratégica } \\
\text { administrativa que esse governo estabelece...” } \\
\text { (Entrevista 7B). }\end{array}$ \\
\hline $\begin{array}{l}\text { Perfil do servidor } \\
\text { (aluno) }\end{array}$ & $\begin{array}{l}\text { Seleção do aluno vocacionado. } \\
\text { Seleção do aluno empático ao } \\
\text { serviço público. } \\
\text { Observação dos princípios da } \\
\text { andragogia. }\end{array}$ & $\begin{array}{l}\text { Obtenção da autoeficácia } \\
\text { empreendedora e } \\
\text { autorrealização do aluno. }\end{array}$ & $\begin{array}{l}\text { "...os valores, geração de valor público, } \\
\text { experimentação, atuação em rede, empatia, abertura } \\
\text { ao risco que você falou proatividade e colaboração. } \\
\text { Sim porque proatividade ali eu acho que talvez seja } \\
\text { o momento empreendedorismo..." (Entrevista 17A). }\end{array}$ \\
\hline $\begin{array}{l}\text { Educação } \\
\text { empreendedora }\end{array}$ & $\begin{array}{l}\text { Aplicação de metodologias } \\
\text { ativas: Dinâmicas de grupo, } \\
\text { benchmarking e effectuation. }\end{array}$ & $\begin{array}{l}\text { Diversificação das } \\
\text { estratégias, métodos } \\
\text { e ferramentas de } \\
\text { aprendizagem }\end{array}$ & $\begin{array}{c}\text { “...a escola de governo está se abrindo para } \\
\text { as tecnologias ativas de ensino e aprendizagem. } \\
\text { A gente está se abrindo, por exemplo: o design } \\
\text { thinking, a gente tá se abrindo isso já tem lá } \\
\text { no governo, design thinking. Oh nessa superintendência } \\
\text { de inovação que eu estou te falando, que é tocada por } \\
\text { alunos daqui..." (Entrevista 6B) }\end{array}$ \\
\hline
\end{tabular}




\begin{tabular}{|c|c|c|c|}
\hline $\begin{array}{l}\text { Aspectos } \\
\text { jurídicos legais/ } \\
\text { Órgãos de } \\
\text { controle }\end{array}$ & $\begin{array}{l}\text { Estabelecimento de cursos } \\
\text { específicos. } \\
\text { Trabalho conjunto com o staff } \\
\text { jurídico. } \\
\text { Formação de parcerias } \\
\text { externas para cocriação, } \\
\text { entreajuda e coparticipação. }\end{array}$ & Mitigação de riscos. & $\begin{array}{c}\text { "... a lei ela permite interpretações, então, ao } \\
\text { interpretar a lei a escola de governo pode usar } \\
\text { princípios da administração pública que nos ajudam } \\
\text { a atuar com maior eficiência e flexibilidade. } 0 \\
\text { agente público, às vezes ele fica muito amarrado..." } \\
\text { (Entrevista 08B) }\end{array}$ \\
\hline $\begin{array}{l}\text { Adequação da } \\
\text { infraestrutura }\end{array}$ & $\begin{array}{l}\text { Estabelecimento de um } \\
\text { laboratório de inovação. }\end{array}$ & $\begin{array}{l}\text { Desenvolvimento } \\
\text { de experiências e } \\
\text { criatividade. } \\
\text { Formação de um mindset } \\
\text { de inovação. }\end{array}$ & $\begin{array}{l}\text { “...e então, a escola de governo desenvolveu esse } \\
\text { sistema de gestão acadêmica só pra atender os } \\
\text { cursos de formação. Ficou espetacular, um } \\
\text { sistema muito bem feito. Ah estamos aprimorando o } \\
\text { nosso portal aprender ..." (Entrevista 11C). }\end{array}$ \\
\hline $\begin{array}{l}\text { Competência } \\
\text { do facilitador } \\
\text { (professor) }\end{array}$ & $\begin{array}{l}\text { Formação de lideranças. } \\
\text { Mentoring. }\end{array}$ & $\begin{array}{l}\text { Encorajamento para a } \\
\text { ação. }\end{array}$ & $\begin{array}{l}\text { "...tantos outros que tem na internet são ótimos, } \\
\text { mas o mais forte é o modelo mental, o mais forte é } \\
\text { a escola de governo encorajar as pessoas } \\
\text { a desenvolver competências. O que me parece que } \\
\text { vocês chamam empreendedores..." (Entrevista 19A). }\end{array}$ \\
\hline
\end{tabular}

Fonte: Elaborado pelos autores a partir dos dados da pesquisa

\section{Educação para o Empreendedorismo no Setor Público - EpESP}

O primeiro passo seria um posicionamento quanto à decisão ou não de se trabalhar uma Educação em Empreendedorismo para o Setor Público. Será que faz sentido? Há lógica nessa proposta? Determinadas pressões do ambiente externo e as ações de organismos multilaterais como a Organização para Cooperação e Desenvolvimento Econômico (OCDE) têm alertado sobre a importância dessa agenda para a Administração Pública (OCDE, 2017). Zampetakis e Moustakis (2010), reconhecem que até o momento não existe um modelo formal sobre como se realizar o empreendedorismo no setor público.

Não obstante, a AFC sinaliza por meio das classes 1, 2 e 5 que já existe um movimento educacional nas Escolas de Governo direcionado para a formação empreendedora do aluno. Porém, percebe-se que a conotação da EpESP está sendo feita de forma velada, caracterizando assim um pseudo empreendedorismo que muitas vezes é tratado como uma ação para a inovação. Assim, percebe-se que ações pró intraempreendedorismo no setor público podem ser observadas à medida que as instituições de pesquisas investem nos programas de capacitação para a inovação e para o desenvolvimento de lideranças no setor público (ação proativa para o trabalho). Viver num contexto de incerteza, principalmente com as transições de governo e cortes de gastos inesperados, também fortalece a curva de aprendizagem do intraempreendedorismo. Outro detalhe é que, de modo geral, os entrevistados revelaram-se experientes o suficiente para não terem receio de exposição aos riscos, de enfrentamento de problemas e de limitações no afã de transformá-los em soluções. 


\section{Análise do contexto}

Dependendo da situação, o contexto pode conspirar a favor ou contra as iniciativas intraempreendedoras. Importante considerar aqui a contribuição de Thomassen, Middleton, Ramsgaard, Neergaard e Warren (2019), que dividem o contexto em três níveis de fenômenos sociológicos: o macro, o meso e o micro. No nível macro são considerados os elementos de contexto nacional e internacional. No nível meso, em termos EpE são considerados os elementos de contexto específico regional e universitário. Já o nível micro representa níveis individuais e de pequenos grupos, além de capturar aspectos mais específicos do programa. Neste caso, pode-se observar fatores relacionados à pedagogia e à didática, aos processos de avaliação, ao corpo discente e docente, aos stakeholders e à network (rede), bem como à configuração online. A parte do conteúdo, dos objetivos educacionais e métodos também se inserem neste nível micro.

Desta forma, nota-se que a EpESP é refém de uma perspectiva contextualizada e isso aflorou nas classes 3 e 4 da AFC. Observou-se também em alguns depoimentos dos entrevistados indícios de blindagem das Escolas de Governo, porém todos externaram o receio quanto aos impactos das transições de governo na dinâmica e funcionamento destas instituições. A agenda de prioridades sofre sim interferência da política, da economia, do mercado de trabalho e das contingências das demandas sociais. Portanto, uma proposta de EpESP, dependendo da situação, corre o risco de ser descontinuada, ampliada e ou revogada conforme o caso. Assim, na formação de um servidor intraempreendedor, as Escolas de Governo devem estar atentas à análise do macroambiente, ao desenho de cenários, à observação de elementos nacionais, internacionais, regionais, institucionais e universitários.

Olhar para o contexto externo das Escolas de Governo sensibiliza seus gestores para as demandas do cidadão enquanto usuário dos serviços públicos. Essa perspectiva abre espaço para a identificação de oportunidades e para a criação de valor público por meio do processo de educação empreendedora, bem como vislumbra incertezas e aciona medidas para sua superação.

\section{Aluno interessado, servidor vocacionado - o perfil desejado}

O ideal seria que todo servidor, na condição de aluno, fosse submetido à EpE para aquisição de competências empreendedoras. Entretanto, na prática, isso pode ser contraproducente porque nem todos vão demonstrar, de imediato, interesse pelo processo empreendedor. A análise de similitude deixou esse aspecto evidente quando associou "pessoas" a "resistência", "cultura", "dinheiro" e "interesse". Alguns podem entender como desvio das funções e atribuições do cargo e gerar resistências, ou mesmo especulações de participação forçada em função de recompensas tangíveis. Ainda existem os casos crônicos de natureza ideológica. Portanto, é necessária uma triagem, por meio da psicologia cognitiva (Mendes, 2011) para se detectar o pensamento empreendedor (Bird, 1988) naqueles servidores mais aptos 
a buscarem uma ação empreendedora de fato. Caso contrário, a EpE pode se configurar em apenas divulgação de informações sobre o conteúdo de empreendedorismo sem efeito a posteriori.

Parte-se do pressuposto que um funcionário público realmente vocacionado cria valor público e não só cumpre com exímia eficiência suas tarefas caso seja requisitado. Deve haver empatia (Tavares, 2020) com as necessidades e interesses do cidadão, uma autocrítica que, em muitos casos, suas funções de trabalho estão defasadas e inoperantes e que é necessário proatividade para sair da "zona de conforto" - um dos pontos-chave da andragogia (Forrest \& Peterson, 2006). Outro detalhe é que o servidor deve estar imbuído da busca da autorrealização, pois se ficar "preso" ao comodismo da remuneração compulsória e à estabilidade do cargo, dificilmente vai contribuir com ações intraempreendedoras em sua atividade profissional. Isto é, é necessário canalizar seus esforços, atenção, experiência e ação para um novo panorama de prestação de serviços públicos. Essas diretrizes são promotoras da autoeficácia empreendedora.

\section{A distinção da Educação Empreendedora}

Há de se convir que em pleno século XXI, num cenário de inteligência artificial, tecnologias de informação avançadas, internet, redes sociais virtuais e tudo mais, insistir em métodos tradicionais de ensino e aprendizagem é "correr contra a maré". Ensinar empreendedorismo na base do "cuspe e giz", foi considerado antiquado e improdutivo pelos entrevistados que, ao mesmo tempo, valorizaram o advento das metodologias ativas. Aqui cabe a distinção Educação Empreendedora (entrepreneurial education) (Pham, 2018) e Educação em ou para o Empreendedorismo (entrepreneurship education) (Watson \& McGowan, 2019). A primeira é uma "atividade meio" e está relacionada à ressignificação de métodos e técnicas de ensino e aprendizagem cabíveis em toda e qualquer área do conhecimento. A segunda é uma "atividade fim" e está dotada em fazer com que as pessoas absorvam conhecimento em empreendedorismo.

$\mathrm{Na}$ educação para o empreendedorismo é imperativo o uso das metodologias ativas para que o servidor se beneficie dessas didáticas de transferência de conhecimento e assimilem rapidamente a nova dimensão do seu trabalho intraempreendedor, conforme evidenciado pela classe 2 na AFC. Portanto, é sensato buscar uma aproximação com a iniciativa privada, principalmente com as escolas particulares para se "ventilar" a inovação e a criatividade em termos de retenção da atenção do aluno, ou seja, promover o benchmarking apropriado. São muitas as novas tecnologias e plataformas de ensino que estão revolucionando a educação e que estimulam o intraempreendedor proativamente. A educação empreendedora por meio das metodologias ativas capacita o servidor intraempreendedor a transportar para o seu dia a dia profissional o uso de diversas estratégias e ferramentas de aprendizagem. 


\section{Aspectos jurídicos}

"Ter atitude e ser articulado". Esse mote é a salvaguarda para o servidor que tem o temor de judicialização das suas prováveis iniciativas de intraempreendedorismo nas organizações públicas. A OCDE (2017), fala em insurgência, ou seja, desafiar o status quo e trabalhar com parceiros em comum. A insurgência é uma das seis competências básicas para a inovação no setor público de acordo com o Modelo Beta de habilidades da OCDE. Ela deve ser entendida como um modo de desafiar o jeito usual de fazer a coisas, trabalhar com parceiros diferentes e construir alianças para a mudança (OCDE, 2017, p. 9). Sudirman, Siswanto, Monang e Aisha (2019) comentam sobre as novas competências para os gestores públicos que devem ser obtidas por indução a partir de uma análise temática como a aderência a leis e regulamentos e atitudes colaborativas, por exemplo.

Neste caso, o servidor não pode ser avesso à compreensão aprofundada de leis, normas e regulamentos, conforme evidenciado pelas palavras da classe 4 na AFC. Ele deve procurar uma assessoria jurídica se for o caso, fazer cursos específicos neste quesito e, principalmente, propor uma nova lei caso as vigentes não atendam. O que deve ficar claro é que o servidor não pode querer tirar vantagem própria da situação de inovação que ele propõe, principalmente em relação a benefícios financeiros, ou querer se projetar em cima da sua própria obrigação de servidor. O foco na criação de valor público como prioridade não pode ser negligenciado; desta forma, o intraempreendedorismo público estará assegurado. Com isso, o aspecto jurídico da EpESP proporciona a minimização de riscos.

\section{Adequação da infraestrutura}

Surpreendentemente os entrevistados não demonstram maiores preocupações com a necessidade de um investimento vultoso com a logística e infraestrutura necessária para se promover uma EpESP. Ao que parece, as instituições visitadas são bem aparelhadas neste sentido, com instalações físicas que podem ser aproveitadas, remanejamento de salas que pode ser efetuado e melhorias na tecnologia de informação que podem ser alcançadas sem esforços exagerados. Não se despreza os desafios na adequação da infraestrutura necessária para se operacionalizar um projeto de EpESP, contudo, a criatividade e boa vontade dos entusiastas podem fazer a diferença neste quesito.

A infraestrutura emergiu na análise de similitude por meio da associação das Escolas de Governo aos "laboratórios_de_inovação", ressaltando a relevância da criação desses laboratórios para a formação da visão intraempreendedora durante a EpESP. Esses laboratórios são propulsores do desenvolvimento de experiências e criatividade, bem como da formação de um mindset de inovação.

Zivkovic (2018) comenta sobre a necessidade de uma abordagem sistêmica nos laboratórios de inovação para resolução de problemas complexos e de maior gravidade, exigindo-se a combinação de recursos e esforços (cocriação). Capdevila (2019), faz menções interessantes sobre a 
classificação dos espaços colaborativos e identifica claramente as diferentes possibilidades de inovação a partir desses espaços, como os laboratórios de inovação.

\section{O papel dos facilitadores}

Krueger, Reilly e Carsrud (2000) valorizam o papel dos educadores como facilitadores no impulsionamento do intraempreendedorismo por meio de um processo educativo típico. Esses agentes podem entender melhor as motivações e intenções dos alunos e assim fornecer um treinamento mais customizado e de maior eficácia. É importante que os professores tenham uma força de diagnóstico para analisar os casos de ensino e aprendizagem em vigor, além de avaliar os resultados e saber extrair o melhor potencial dos alunos. As orientações e os cursos de ação dos estudantes podem ser influenciados por iniciativas desejáveis de mentores que atuam de forma cativante e inspiradora sobre os seus discípulos, estando envolvidos em fluxos de recursos e informações.

Em complementariedade, muitos autores compreendem que o papel dos facilitadores do empreendedorismo no setor público está ligado à formação de lideranças como assinala Mau (2019), como um staff precioso no contexto da inovação governamental. Nesse propósito, a mentoria (Jones, 2018) gera o encorajamento para a ação do empreendedorismo, que no seio das organizações públicas já existentes enaltecem o intraempreendedorismo por meio da aquisição compulsória e novas habilidades e competências. A classe 2 da AFC ressaltou a importância das pessoas, facilitadores e alunos na EpESP.

\section{Conclusão}

Tradicionalmente, as Escolas de Governo são instituições públicas autorizadas por lei a profissionalizar o capital humano que atua no interior dos diferentes órgãos governamentais. Elas atuam na formação, capacitação e qualificação constante dos funcionários públicos, atualizando-os em relação a novas habilidades e competências, dentre as quais estão as competências empreendedoras. O aporte incremental de habilidades empreendedoras nos servidores públicos eleva-os à condição de intraempreendedores do setor público - mais do que técnicos burocratas - uma vez que eles empreendem mudanças e aperfeiçoamentos de forma inovadora dentro de uma organização pública preexistente e não fora dela.

Compreendendo-se que as Escolas de Governo têm um papel de vanguarda na assimilação dessa temática e na tradução do empreendedorismo em linhas de educação para o revigoramento da força de trabalho atuante no setor público, foi proposto este estudo. Seu objetivo é detectar evidências de diretrizes educativas e formativas em prol do intraempreendedorismo no setor público por intermédio das Escolas de Governo. Ele consta do estudo de caso de três Escolas de Governo do executivo nacional, estadual e municipal, sendo, respectivamente, 
a ENAP (Brasília-DF), a Fundação João Pinheiro (Belo Horizonte-MG) e o IMAP (Curitiba-PR). Trata-se de instituições proeminentes no setor, cujos representantes entrevistados sinalizaram a medida de absorção do empreendedorismo nestas organizações e as diretrizes de Educação para o Empreendedorismo no Setor Público (EpESP).

Os resultados apurados revelaram que muita coisa tem sido feita. Não com o rótulo específico de empreendedorismo, mas de forma fragmentada, com ênfase nos seus principais determinantes como inovação e formação de liderança. Também não passam desapercebidos os programas, cursos e projetos propostos para orientar os servidores quanto ao preparo para a atenção para as oportunidades e para o processo decisório num contexto de incertezas e riscos, principalmente dos processos administrativos.

A investigação destas Escolas de Governo gerou uma série de insights e recomendações que, uma vez organizadas, podem se tornar diretrizes para o início de uma EpESP. Tal procedimento envolve constructos que, se bem trabalhados e incrementados, podem gerar resultados de sucesso na criação de valor público. Destacam-se assim a análise do contexto, o perfil do aluno (servidor), os métodos revolucionários de ensino, a aprendizagem da educação empreendedora, a questão dos aspectos jurídicos-legais, a adequação da infraestrutura e o papel dos facilitadores (professores).

À medida em que essas diretrizes forem implementadas, um processo legítimo de educação para o empreendedorismo no setor público emerge. Com isso, o servidor (funcionário público) seria beneficiado com novas competências e habilidades e, sobretudo, com um novo olhar sobre a coisa pública. Isso significa o desenvolvimento da capacidade intraempreendedora do servidor público. A relação entre a educação para o empreendedorismo e o intraempreendedorismo do servidor público é representada por meio do modelo desenhado na Figura 4.

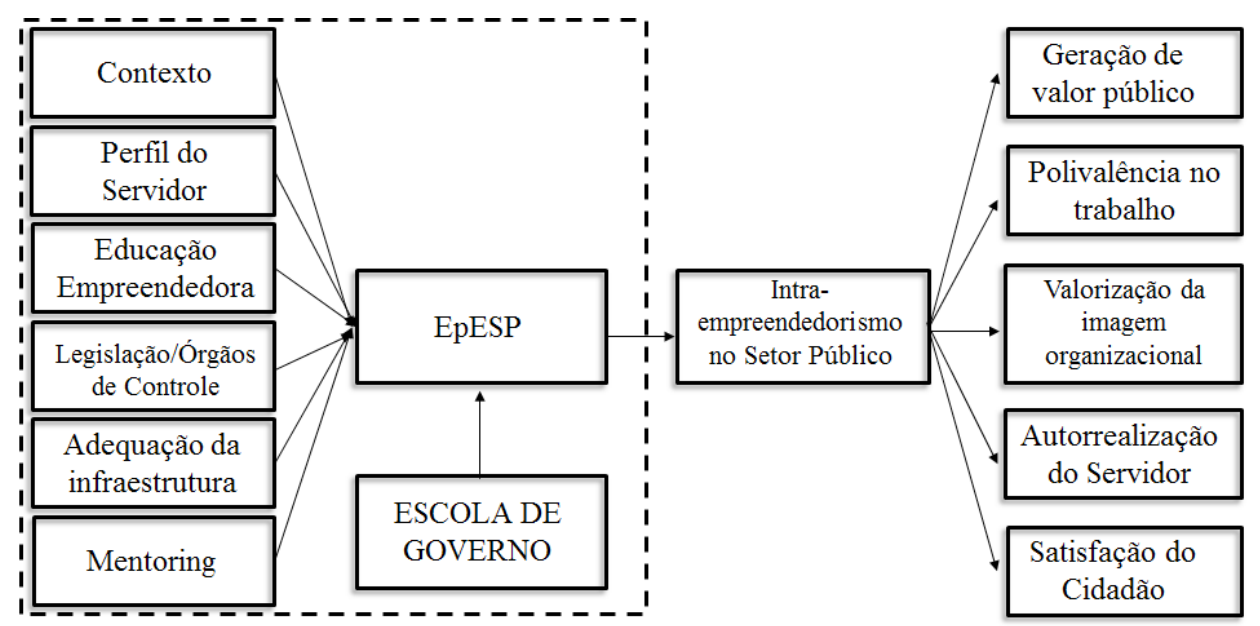

Figura 4. Diretrizes de ações formativas e educativas das Escolas de Governo em prol do intraempreendedorismo no setor público.

Fonte: Elaborada pelos autores a partir dos dados da pesquisa

Enfim, uma vez colocada em prática a EpESP, não de forma mascarada ou subliminar, mas legitimada por uma andragogia do empreendedorismo de vigor, entende-se que haverá uma proliferação do intraempreendedorismo no setor público que acarretará inúmeros benefícios. Às organizações 
públicas incorreria a melhoria dos seus processos intraorganizacionais e o atendimento à contento das demandas sociais por meio da geração do valor público. Aos servidores aumentaria a sua polivalência para o trabalho e principalmente a contemplação de sua autorrealização. Ademais, seguramente sua imagem perante à opinião pública também seria mais valorizada. Para as Escolas de Governo seria uma oportunidade de um maior protagonismo na ressignificação da Administração Pública brasileira e maior projeção institucional dessas organizações. Desmistificar essa relação da aderência do empreendedorismo no setor público também seria um fator de destaque e um passo importante para a prosperidade.

Sendo este trabalho de cunho exploratório, não poderia deixar de emergir algumas questões para estudos futuros. Portanto, sugere-se como uma contrapartida para o estudo aqui realizado, uma pesquisa qualitativa de cunho exploratório junto aos servidores que passaram pelas Escolas de Governo. Seu objetivo poderia ser captar a percepção desses ex-alunos quanto às diretrizes para a EpESP das Escolas de Governo, a fim de verificar se a oferta de uma proposta de educação pelo empreendedorismo é efetivamente percebida por seu público-alvo.

Segundo, recomenda-se um estudo de natureza quantitativa para testar se a educação para o empreendedorismo no setor público corrobora para intraempreendedorismo na prática profissional do servidor. Neste contexto algumas hipóteses de pesquisa são sugeridas: (1) o aluno (servidor) com perfil vocacionado para o empreendedorismo desenvolve o intraempreendedorismo em sua prática profissional; (2) o aluno (servidor) empático ao serviço público desenvolve o intraempreendedorismo em sua prática profissional; (3) o aluno (servidor) sujeito à metodologias ativas de ensino desenvolve o intraempreendedorismo na sua prática profissional; (4) o aluno (servidor) habilitado por laboratórios de inovação desenvolve o intraempreendedorismo em sua prática profissional; (4) o aluno (servidor) sujeito a um processo educativo por mentoria desenvolve o intraempreendedorismo em sua prática profissional.

Terceiro, levando em consideração que a autoeficácia é a confiança que um indivíduo tem em sua capacidade de lidar com tarefas ou problemas difíceis (Bandura, 1977) e que a autoeficácia ocupacional (Rigotti, Schyns, \& Mohr, 2008) juntamente com os traços da personalidade (Ourique \& Teixeira, 2012) são fatores determinantes do planejamento da carreira profissional, seria possível pensar em um estudo com modelagem de equações estruturais para investigar a relação da autoeficácia ocupacional e dos traços de personalidade sobre a atitude empreendedora dos gestores públicos.

Por fim, dado que o método de pesquisa aqui empregado é de natureza qualitativa, há que se considerar as limitações que impedem a generalização de seus resultados em duplo sentido. Primeiro, considerar que as diretrizes aqui encontradas emergem em todas as Escolas de Governo brasileiras. Segundo os pesquisadores que desejam replicar esse estudo são aconselhados a observar as diferenças do contexto cultural dos entrevistados e as condições das entrevistas. 


\section{Referências}

Abdolhosseinzadeh, M., \& Abdolhamid, M. (2020). Presentation of a school of government model through a comparative study of selected schools. Kybernetes, ahead-of-p (ahead-of-print). https://doi.org/10.1108/K-05-2019-0328

Arnold, A. (2019). Being alert: bridging theory and practice in public sector entrepreneurship. International Journal of Public Sector Management, 32(7), 706-720. https://doi.org/10.1108/IJPSM-11-2018-0239

Bandura, A. (1997). Self-efficacy: the exercise of control. New York: W.H. Freeman and Company.

Bandura, A. (1977). Self-efficacy: toward a unifying theory of behavioral change. Psychological Review, 84(2), 191-215. https://doi.org/10.1016/01466402(78)90002-4

Bardin, L. (2016). Análise de conteúdo. São Paulo: Edições 70.

Bird, B. (1988). Implementing entrepreneurial ideas: the case for intention. Academy of management Review, 13(3), 442-453. https://doi.org/10.5465/amr.1988.4306970

Braunerhjelm, P., Ding, D., \& Thulin, P. (2018). The knowledge spillover theory of intrapreneurship. Small Business Economics, 51(1). https://doi.org/10.1007/s11187017-9928-9

Brito, L. M. (2019). Elementos de influência no apego ao lugar de destino pelos turistas em Minas Gerais. Tese de Doutorado, Fundação Getúlio Vargas, São Paulo, SP, Brasil.

Cabral, S., \& Ménard, C. (2019). Managing critical services through hybrid arrangements. RAUSP Management Journal, 54(3), 337-356. https://doi. org/10.1108/RAUSP-03-2019-0037

Camargo, B. V. (2005). ALCESTE: Um programa informático de análise quantitativa de dados textuais. In A. S. P.Moreira, B. V. Camargo, J. C. Jesuíno \& S. M. Nóbrega (Eds.). Perspectivas teórico-metodológicas em representações sociais (pp. 511539). João Pessoa, PB: Editora da Universidade Federal da Paraíba.

Camargo, B. V., \& Justo, A. M. (2013). IRAMUTEQ: um software gratuito para análise de dados textuais. Temas Em Psicologia, 21(2), 513-518. https://doi.org/10.9788/ tp2013.2-16

Capdevila, I. (2019). Joining a collaborative space: Is it really a better place to work? Journal of Business Strategy, 40(2), 14-21. https://doi.org/10.1108/JBS-09-20170140

CE - Comissão Europeia. (2006). Comunicação da Comissão ao Conselho, ao Parlamento Europeu, ao Comitê Econômico e Social Europeu e ao Comitê das Regiões, Aplicar o Programa Comunitário de Lisboa: promover o espírito empreendedor através do ensino e da aprendizagem, Bruxelas. 46.

Duarte, J. Entrevista em profundidade (2011). In J. Duarte \& A. Barros (Orgs.). Métodos e técnicas de pesquisa em comunicação (2. Ed., pp. 62-83) São Paulo: Atlas.

Edoho, F. M. (2016). Entrepreneurship paradigm in the new millennium: a critique of public policy on entrepreneurship. Journal of Entrepreneurship in Emerging Economies, 8(2), 279-294. https://doi.org/10.1108/JEEE-08-2015-0043 
EMERALD - Emerald Publishing Limited. (2019). In the public eye: entrepreneurial behaviour in the public sector. Strategic Direction, 36(1), 1-3. https://doi.org/10.1108/ SD-10-2019-0186

Emmendoerfer, M. L. (2019). Inovação e empreendedorismo no setor público. Brasília: ENAP. https://doi.org/10.5281/zenodo.4236805

Evaristo, J. L. S., Batista-dos-Santos, A. C., Aguiar, R. G., Souza, J. C., \& Franco, A. F. M. (2019). Escolas de governo e seu papel estruturante na formação de servidores em tempos de Nova Gestão Pública: relatos de experiências no Nordeste brasileiro. Rev. Serv. Público Brasília, 70, 107-131.

Fayolle, A. (2000). Eexploratory study to assess the effects of entrepreneurship rograms on french student entrepreneurial behaviors. Journal of Enterprising Culture, 8(2), 169-184. Retrieved from www.worldscientific.com

Fellnhofer, K. (2019). Toward a taxonomy of entrepreneurship education research literature: a bibliometric mapping and visualization. Educational Research Review, 27, 28-55. https://doi.org/10.1016/j.edurev.2018.10.002

Fonseca, D. R., Camões, M. R. S., Cavalcante, P. L. C., Lemos, J., \& Palotti, P. (2019). Schools of government's roles and challenges for institutionalization: a comparative study in the brazilian federal public Sector. Rev. Serv. Público Brasilia, 70, 71-106. https://doi.org/10.21874/rsp.v70i0.1458

Fonseca, D. R., Meneses, P. P. M., Souza, I. G. L., \& Hollanda, P. P. T. M. de. (2019). Escolas de governo e redes de capacitação no setor público: perspectivas metodológicas para governança. Rev. Serv. Público Brasília, 70, 34-70. https://doi. org/10.21874/rsp.v70i0.1479

Forrest, S. P., \& Peterson, T. O. (2006). It's called andragogy. Academy of Management Learning \& Education, 5(1), 113-122.

Franco, M. L. P. B. (2018). Análise de conteúdo (5a Ed.). Campinas: Autores Associados.

Fuller, C., \& DelliSanti, D. (2017). Spillovers from public entrepreneurship: a case study. Journal of Entrepreneurship and Public Policy, 6(1), 72-91. https://doi.org/10.1108/ JEPP-03-2016-0010

Godoi, C. K., \& Mattos, P. L. C. L. (2010). Entrevista qualitativa: instrumento de pesquisa e evento dialógico. In C. K. Godoi, R. Bandeira-de-Melo, \& A. B. Silva (Eds.), Pesquisa qualitativa em estudos organizacionais: Paradigmas, estratégias e métodos (2. Ed., pp. 460). São Paulo: Saraiva.

Gomes, R. K. (2017). Melhores práticas intraempreendedoras para a gestão pública: um estudo de multicasos. Tese de Doutorado. Universidade Federal de Santa Catarina.Florianópolis, SC, Brasil.

Gomes, R. K., Consoni, D. P. G., \& Laplli, É. M. (2015). Intrapreneurial competence of the public servants of IBGE and IFSC from the perspective of their managers. Business and Management Review, 4(5), 704-712. Retrieved from http://www. businessjournalz.org/bmr

Hägg, G., \& Schölin, T. (2018). The policy influence on the development of entrepreneurship in higher education: a Swedish perspective. Education and Training, 60(7-8), 656-673. https://doi.org/10.1108/ET-07-2017-0104 
Hollanda, P. P. T. M., Cardoso, S. A. A., Fernandes, C. C. C., \& Rosa, C. H. C. (2019). Schools of government: a comparative study. Rev. Serv. Público, 70, 15-33. https:// doi.org/10.21874/rsp.v70i0.1514

Jones, J. (2018). How can leaders and managers in the Police support the learning of others and at the same time, support their own? International Journal of Emergency Services, 7(3), 228-247. https://doi.org/10.1108/IJES-04-2017-0026

Krueger Jr., N. F., Reilly, M. D., \& Carsrud, A. L. (2000). Competing models of entrepreneurial intentions. Journal of Business Venturing, 15, 411-432.

Leyden, D. P., \& Link, A. N. (2015). Public sector entrepreneurship: U.S. technology and innovation policy. New York: Oxford University Press.

Liddle, J. (2016). Conclusion: public sector entrepreneurship. The future research agenda. Contemporary Issues in Entrepreneurship Research, 6, 237-245. https:// doi.org/10.1108/s2040-724620160000006020

Liddle, J., \& McElwee, G. (2019). Theoretical perspectives on public entrepreneurship. International Journal of Entrepreneurial Behaviour and Research, 25(6), 1308-1320. https://doi.org/10.1108/JJEBR-02-2019-0067

Lopes, R. M. A., \& Lima, E. (2019). Desafios atuais e caminhos promissores para a pesquisa em empreendedorismo. RAE Revista de Administracao de Empresas, 59(4), 284-292. https://doi.org/10.1590/S0034-759020190406

Lubienski, C., \& Perry, L. (2019). The third sector and innovation: competitive strategies, incentives, and impediments to change. Journal of Educational Administration, 57(4), 329-344. https://doi.org/10.1108/JEA-10-2018-0193

Matus, C. (2007). Escuela de gobierno. Salud Colectiva, 3(2), 203-212.

Mau, T. A. (2019). Enhancing leadership capacity in the public sector: branding as an employer of choice. International Journal of Public Leadership, 15(3), 155-169. https://doi.org/10.1108/ijpl-05-2019-0019

Mazieri, M. R. (2016). Patentes e inovação frugal em uma perspectiva contributiva. Tese de doutorado, Universidade Nove de Julho, São Paulo, SP, Brasil.

Mazzucato, M. (2014). O estado empreendedor. São Paulo: Portfolio-Penguin.

Mendes, M. T. T. (2011). Educação empreendedora: uma visão holística do empreendedorismo na educação. Dissertação de Mestrado, Universidade Católica Portuguesa, Lisboa, Portugal.

Moser, A., \& Korstjens, I. (2018). Sampling, data collection and analysis. European Journal of General Practice, 24(1), 9-18. https://doi.org/10.1080/13814788.2017.1 375091

Mustafa, M., Gavin, F., \& Hughes, M. (2018). Contextual determinants of employee entrepreneurial behavior in support of corporate entrepreneurship: a systematic review and research agenda. Journal of Enterprising Culture, 26(03), 285-326. https://doi.org/10.1142/s0218495818500115

Najmaei, A., \& Sadeghinejad, Z. (2016). Toward a theory of business models and business modeling in public entrepreneurship. Contemporary Issues in Entrepreneurship Research, 6, 77-102. https://doi.org/10.1108/S2040724620160000006004 
Nascimento, A. R. A., \& Menandro, P. R. M. (2006). Análise lexical e análise de conteúdo: uma proposta de utilização conjugada lexical. Estudos e Pesquisas Em Psicologia, 6(2), 72-88.

Nayak, B. S. (2019). Reification and praxis of public private partnerships in history. Society and Business Review, 14(1), 63-70. https://doi.org/10.1108/SBR04-2018-0034

Neto, A. P., Emmendoerfer, M. L., \& Corrêa, S. C. H. (2020). Entrepreneurship education guidelines in the public sector: the perspective of government schools. Journal of Accounting, Management and Governance, 23(3), 405-423. http://dx.doi. org/10.51341/1984-3925_2020v23n3a7

OCDE. (2017). Core skills for public sector innovation. In Skills for a High Performing Civil Service. OECD Publishing: Paris. https://doi.org/10.1787/9789264280724-6en.

Ourique, L. R., \& Teixeira, M. A. P. (2012). Autoeficácia e personalidade no planejamento de carreira de universitários. Psico-USF, 17(2), 311-321. https://doi. org/10.1590/s1413-82712012000200015

Pacheco, R. S. (2000). Escolas de governo: tendências e desafios-ENAP-Brasil em perspectiva comparada 1. Revista Do Serviço Público, 51(2), 35-53. https://doi. org/10.21874/rsp.v51i2.324

Paula, A., Emmendoerfer, M. L., \& Azevedo, J. P. A. (2018). Determinantes da educação para o empreendedorismo (EpE): proposição e discussões. In A. Shigunov Neto \& I. Furtado (Eds.), O ensino do empreendedorismo: Passado, presente, perspectivas (p. 183). Retrieved May, 19, 2020, from http://nutecca.webnode.com.br Pham, D. (2018). Contemporary issues in entrepreneurship research volume 7. Entrepreneurship education: new perspectives on research, policy \& practice. International Journal of Entrepreneurial Behavior \& Research, 24(1), 317-319. https:// doi.org/10.1108/ijebr-01-2018-426

Prieto, L. C., Phipps, S. T. A., \& Kungu, K. (2020). Facilitating a culture of intrapreneurship: an employee involvement approach. Strategic HR Review, 19(2), 93-95. https://doi.org/10.1108/shr-04-2020-181

Pugalis, L., Davidson, J., McLeay, F., \& Round, A. (2016). Tough times, difficult choices and public entrepreneurship: is sponsorship a winning solution? Contemporary Issues in Entrepreneurship Research, 6, 37-59. https://doi.org/10.1108/S2040724620160000006002

Puni, A., Anlesinya, A., \& Korsorku, P. D. A. (2018). Entrepreneurial education, self-efficacy and intentions in Sub-Saharan Africa. African Journal of Economic and Management Studies, 9(4), 492-511. https://doi.org/10.1108/ AJEMS-09-2017-0211

Quinn, M., \& Courtney, R. (2016). The public sector as an entrepreneur? Contemporary Issues in Entrepreneurship Research, 6, 127-146. https://doi.org/10.1108/S2040724620160000006006

Ramos, C. M. O., Feijão, G. M. M., \& Melo, C. F. (2020). As vivências do luto do paciente oncológico. Alternativas En Psicología, 43, 91-116.

Ratinaud, P., \& Déjean, S. (2009). IRaMuTeQ: implémentation de la méthode ALCESTE d'analyse de texte dans un logiciel libre. Modélisation appliquée aux sciences humaines et sociales MASHS, 8-9. 
Rigotti, T., Schyns, B., \& Mohr, G. (2008). A short version of the occupational self-efficacy scale: structural and construct validity across five countries. Journal of Career Assessment, 16(2), 238-255. https://doi.org/10.1177/1069072707305763

Rocha, A. (2012). Educação para o empreendedorismo: intenções empreendedoras dos estudantes do ensino secundário. Dissertação de Mestrado, Universidade da Beira Interior, Covilhã, Portugal.

Saegebrecht, F., John, C., Schmiedgen, P., \& Noennig, J. R. (2019). Experiences and outcomes from a traveling innovation lab experiment. Measuring Business Excellence, 23(2), 121-135. https://doi.org/10.1108/MBE-11-2018-0101

Shand, R., \& Hyde, M. (2016). Can enterprise be a vocation, or is it the end of public service? Contemporary Issues in Entrepreneurship Research, 6, 61-75. https://doi. org/10.1108/S2040-724620160000006003

Souza, M. A. R., Wall, M. L., Thuler, A. C. M. C., Lowen, I. M. V., \& Peres, A. M. (2018). O uso do software IRAMUTEQ na análise de dados em pesquisas qualitativas. Revista da Escola de Enfermagem da USP, 52, 1-7. https://doi.org/10.1590/S1980220X2017015003353

Strategic Direction. (2020). In the public eye: entrepreneurial behaviour in the public sector. Strategic Direction, 36(1), 1-3. https://doi.org/10.1108/SD-10-2019-0186

Sudirman, I., Siswanto, J., Monang, J., \& Aisha, A. N. (2019). Competencies for effective public middle managers. Journal of Management Development, 38(5), 421-439. https:// doi.org/10.1108/JMD-12-2018-0369

Swayne, N., Selznick, B., McCarthy, S., \& Fisher, K. A. (2019). Uncoupling innovation and entrepreneurship to improve undergraduate education. Journal of Small Business and Enterprise Development, 26(6-7), 783-796. https://doi.org/10.1108/ JSBED-04-2019-0122

Tavares, M. (2020, abril 21). Professor de Stanford diz que é possível ensinar empatia. Portal G1 (globo.com). Recuperado em 22 abril, 2020, de https://g1.globo.com/ bemestar/blog/longevidade-modo-de usar/post/2020/04/21/professor-de-stanforddiz-que-e-possivel-ensinar-empatia.ghtml.

Thomassen, M. L., Middleton, K. W., Ramsgaard, M. B., Neergaard, H., \& Warren, L. (2019). Conceptualizing context in entrepreneurship education: a literature review. International Journal of Entrepreneurial Behaviour and Research, 1355-2554. https:// doi.org/10.1108/JJEBR-04-2018-0258

Warner, M. E., Aldag, A. M., \& Kim, Y. (2020). Privatization and intermunicipal cooperation in US local government services: balancing fiscal stres, need and political interests. Public Management Review, 1-19. https://doi.org/10.1080/14719037.202 0.1751255

Watson, K., \& McGowan, P. (2019). Rethinking competition-based entrepreneurship education in higher education institutions: towards an effectuation-informed coopetition model. Education and Training, 62(1), 31-46. https://doi.org/10.1108/ ET-11-2018-0234

Wraae, B., \& Walmsley, A. (2020). Behind the scenes: spotlight on the entrepreneurship educator. Education and Training, 62(3), 255-270. https://doi.org/10.1108/ET-012019-0009

Yin, R. K. (2015). Estudo de caso (5th Ed.). Porto Alegre: Bookman. 
Revista Eletrônica de Ciência Administrativa

585

Zampetakis, L. A., \& Moustakis, V. S. (2010). An exploratory research on the factors stimulating corporate entrepreneurship in the Greek public sector. International Journal of Manpower, 31(8), 871-887. https://doi.org/10.1108/01437721011088557

Zivkovic, S. (2018). Systemic innovation labs: a lab for wicked problems. Social Enterprise Journal, 14(3), 348-366. https://doi.org/10.1108/SEJ-04-2018-0036 